\title{
Autonomous Maintenance: A Case Study on Assela Malt Factory
}

\author{
Melesse Workneh Wakjira and Ananth Shalvapulle Iyengar
}

\begin{abstract}
Purpose: M/S Assela Malt Factory (AMF) is the pioneer in malt supply to the breweries throughout the Ethiopia. The boiler plant faces machines failures, and rate of failures is increasing year after year, which affect the production cost. The important problems of the boiler plant are machine breakdown, machine idle, production loss, too much maintenance man hour, high maintenance expenses, and plant capacity loss. Objective of the research is productivity improvement through identification of problems in machines and the improvement of efficiency, employee's attitude and culture of work.Quality in maintenance and the associated product quality is aimed to be enhanced by application of Autonomous Maintenance (AM) and set maintenance plan for the plant.
\end{abstract}

Design/Methodology/Approach: The study proceeded with observation, data collection, related literature review; document analysis, interview, and giving training for the operators to embark upon $5 S$ implementation at boiler house. A three steps approach for maintenance and improvement of the machine were implemented. First to set the cleaning procedure for the machine and work place, inspection and check for the cause of breakdown and initiate corrective action by maintenance, and final to assign the standard plan for maintenance.

Findings and Originality/Value: This plan has resulted in remarkable improvements in maximum effectiveness of equipment, tidier workplace and morally boosted employees. This project was completed within 18 months and results of research are following conclusion. Breakdown was decreased about $46.38 \%$ per month. Average capacities were increased about $8.75 \%$ per month. Production capacities were increased about $4.85 \%$ per month. Machine idle was decreased about 8.01per month. Maintenance man-hours were decreased about $22.93 \%$ per month. Maintenance expense was decreased from begin start the project about $64.42 \%$.

Originality/Value: Ethiopian manufacturing industries needs a grass root level improvement. Implementation of $5 \mathrm{~S}$, $T P M$, and AM forms the basis for a clear path for growth and sustainability. The key success factors are identified and

Melesse Workneh Wakjira, Mechanical and Vehicle Engineering Department, Adama Science and Technology University, Adama City, Ethiopia.E-mail:melewine@yahoo.com

Ananth Shalvapulle Iyengar, Assistant Professor, Mechanical and Vehicle Engineering Department, Adama Science and Technology University, AdamaCity,Ethiopia.E-mail:dr.iyengar@yahoo.com

DOI: 10.9756/BIJIEMS.10364 reported in this paper and a clear implementation steps are also provided for an Ethiopian process industry framework.

Keywords--- Assela Malt Factory, Boiler Plant, Autonomous Plant, Maintenance Plan

\section{INTRODUCTION}

T $\mathrm{N}$ the study of manufacturing engineering and industrial production, total productive maintenance (TPM), is used to improve production and reduce the cost of production. TPM is a concept aimed at significantly increasing the production in a manufacturing plant, while keeping the machine maintenance costs low. TPM also ensures high employee job satisfaction and customer satisfaction. TPM identifies sixteen types of losses, which fall under the categories of equipment, people, material and safety and suggests improvements in different practices in operation of the factory and machines. These operational practices are also called pillars of TPM. These pillars are autonomous maintenance, focused maintenance, planned maintenance, quality maintenance, education and training, office TPM, development management and safety, health and environment.

Several factors are responsible for the increased cost and time delays on the shop floor. A quick look at the literature clearly states the reasons for such delays. Among these reasons, machine maintenance is the primary cause of delays, lower customer satisfaction and poor quality of products. The losses due to these factors can cause equipment losses and plant losses. Originally equipment losses were categorized into six major types, equipment failure, setup and adjustment, idling and minor stoppages, reduced speed, defects in process, and reduced yield. [1], [2]Additionally, plant losses can be of eight important kinds namely, shutdown, production adjustment, equipment failure, process failure, normal production loss, abnormal production loss, quality defects, and reprocessing. [3] These plant losses were further expanded to sixteen types to include human effectiveness losses such as management losses, motion losses, arrangement losses, loss due to lack of automated systems and monitoring and adjustment losses. [4]

Case studies reported in literature show a coherent set of improvement techniques are necessary to bring about changes in the plant. Improvements in overall equipment effectiveness (OEE) and TPM can reduce the equipment losses. Methods like statistical process control (SPC), and automated process control (APC) can lead to an introduction of integrated process control (IPC) that can improve the quality of product and reduce plant losses. [5], [6]A new algorithm was reported that 
enables the estimation of the mean effective process time $t$ (e) and the coefficient of variation $\mathrm{c}(\mathrm{e})$ of a multiple machine workstation from real data in a semiconductor industry. [7]The results reported from the simulation further corroborate the essential points about OEE, TPM and automation and systematic improvements required in the plant. The effectiveness and implementation of the TPM program for an electronics manufacturing company has also been studied and reported with similar outcomes. [8]Recently, a case study reported show remarkable improvement in OEE through lowering the number of fugai (breakdown) in a tool room organization. [9] An OEE solution can enable manufacturers to achieve world-class status. More specifically it can provide benefits in four key areas; equipment (reduced equipment downtime and maintenance cost, plus better management of the equipment life cycle), personnel (labor efficiencies and increased productivity by improving visibility into operations and empowering operators), (increased productivity by identifying bottlenecks), and quality (increase rate of quality and reduce scrap). [10]It is important to understand the causal factors for such effectiveness losses. Only by eliminating the causes can a sustainable improvement in effectiveness be achieved. The causal factors for the loss of effectiveness may be categorized as:

- A single causal factor for the effectiveness loss.

- Multiple two or more causal factors combined result in the effectiveness loss.

- Complex the interaction between two or more causal factors results in the effectiveness loss

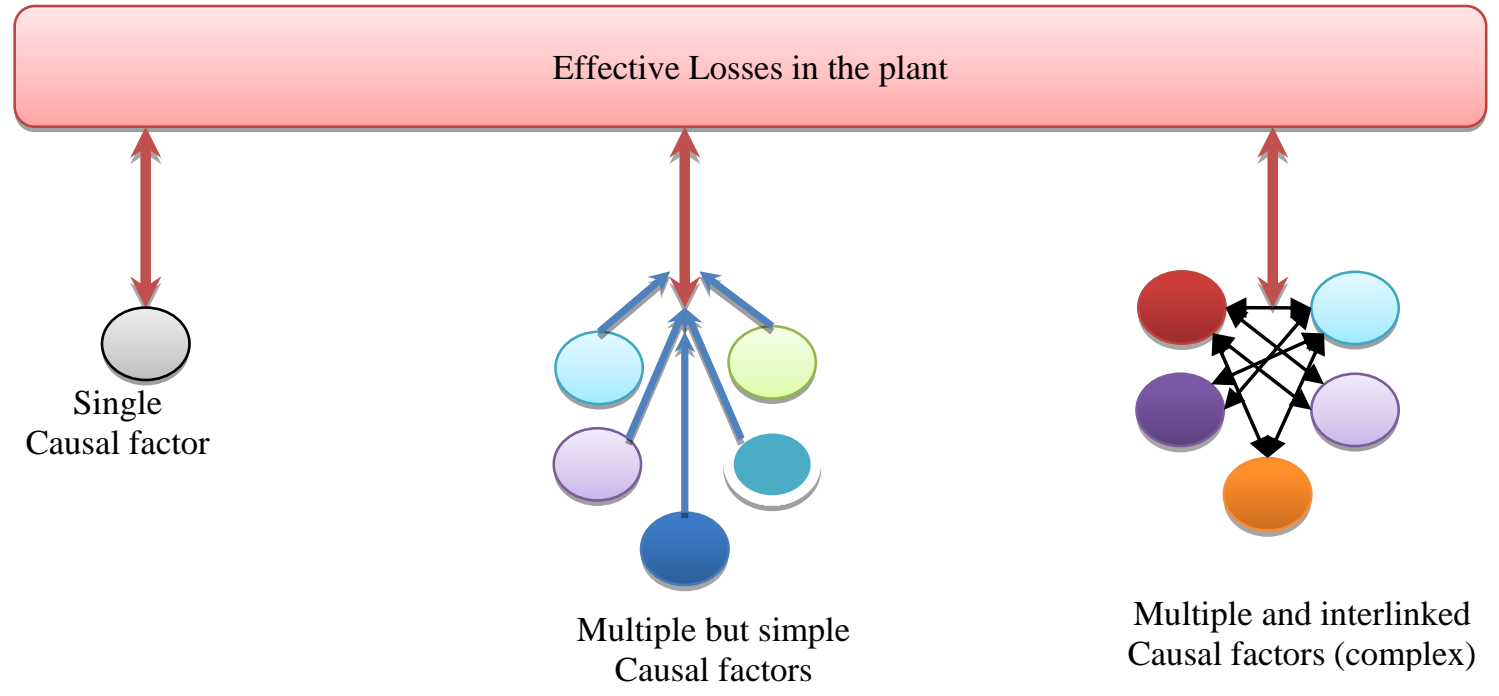

Figure 1: Categories of Causal Factors for Loss of Effectiveness

\section{Autonomous MaintenANCE}

Autonomous maintenance (AM) is one of the pillars of TPM. It follows a structured approach to machine and process maintenance, which increases the skill levels of personnel to understand, manage and improve their equipment and processes. The operators' role is changed from being reactive during machine breakdown to a more proactive in machine maintenance. This facilitates a smoother process flow; achieve optimal conditions for production of high quality end-product without delays. The autonomous maintenance also eliminates minor equipment shutdowns and faster recovery from a machine breakdown.

To understand the importance of AM, we need to look at maintenance procedure followed in the early parts of $20^{\text {th }}$ century. Huge plants were already established after the industrial revolution, and maintenance was done by dedicated, highly skilled employees. The machine operators were expected to wait for the maintenance personnel to rectify minor breakdowns while they were around the equipment all of the time. This leads to unnecessary delays and reduction in productivity. A drastic change had to be brought about by allowing the machine operators to maintain their machines. The operators have to first identify insufficient lubrication, air leaks, increased machine vibrations because of lose nuts and bolts. The solution to these common problems will be available with the operator because he is in constant interaction with the machine.Operator equipment maintenance is about training operators to care for equipment at the source so as to ensure that basic equipment conditions (no looseness, no contamination, perfect lubrication) are established and maintained. This allows the successful implementation of planned preventive and predictive maintenance to be administered by the maintenance department. AM improves corporate business results and creates pleasant and productive workplace by changing the way people think about and work with equipment throughout the factory. AM is one of the most important basic building blocks maintenance program.

The first stage of operator's training starts when the he / she observe the activities of maintenance personnel. Operators should work closely together with the maintenance personnel, and they can do this in three ways:

- They can alert maintenance people.

- They can provide excellent information.

- They can perform routine maintenance.

AM is a critical first step of TPM and operators must be trained to close the information gap between them and the maintenance staff, making it easier for both to work as one team. 


\section{Steps for AM Implementation}

The steps of AM can broadly categorized into three main activities,

1. Training and education,

2. Teamwork,

3. Housekeeping and employee involvement. [11]

The commitment of top management to smoothen the autonomous maintenance activity should not be underestimated.

Specifically, the AM activities can be divided into seven stages as shown below

1. Conduct initial cleaning and inspection

2. Eliminate sources of contamination and inaccessible areas

3. Develop and test provisional cleaning,

4. Inspection and lubrication up to standards,

5. Conduct general inspections autonomously,

6. Workplace organization and housekeeping, and

7. Fully implement the autonomous maintenance program. [8]

The above seven steps are implemented to progressively increase operator's knowledge, participation and responsibility for their equipment. The steps start with the initial cleaning and progresses towards full self-management. Steps 1 to 3 place priority on abolishing environments that cause accelerated deterioration, reversing deterioration and establishing and maintaining basic equipment conditions. The goals of these steps are to get operators interested in their equipment and help them shake off their self-image as mere button pushers or switch flickers.

In steps 4 and 5, operators are taught about inspection procedures. The goals of these steps are to reduce failures and develop operators who thoroughly understand their equipment.
Last two steps are designed to upgrade autonomous maintenance and improvement activities by standardizing systems and methods. The ultimate goal of these steps is a robust organization and culture in which every workplace is full of self-management.

\section{Step 1: Performing an initial cleaning and inspection}

In a functional production plant the AM starts with the existing list of daily and weekly inspection tasks. First, a cleaning procedure for each work station and the whole production line is setup. The maintenance work is helped by the maintenance personnel. Effort is made toeliminate dust and dirt from the main body of the equipment.Common minor defects and breakdown causes areexposed to the maintenance personnel. Care is taken to reach the inaccessible places for cleaning and contamination sources are reduced or eliminated. Unnecessary and seldom used items are placed in suitable places and simplify the equipment operation area. The AM initial clean is part of the early AM training and is performed by a small team that includes the operators, maintenance personnel, the area production supervisor, and others with a vested interest in performance of the production area. A qualified AM trainer should act as facilitator for the initial clean activity. [5]

Performing the initial cleaning and inspection eliminates sources of contamination, clears some of the inaccessible areas. It gives a planned approach to test provisional cleaning, and inspection procedure. Operators learn to conduct general inspections autonomously, workplace organization and housekeeping. It paves way for the full implementation the autonomous maintenance program. To indicate the value of initial cleaning under implementing AM program,the following picture shows clearly the role of initial cleaning in AM.

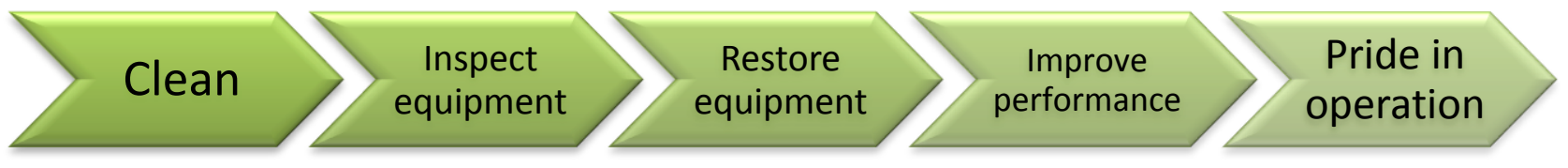

Figure 2: The effects of good Initial Cleaning in Autonomous Maintenance [12]

Initial cleaning is the most difficult job for operators, compared to other tasks in AM. But its role in complete implementation of AM is the highest. During the initial cleaning by the operators a great impact on the equipment performance and productivity can be observed.

Step 2: Establishing counter measures for the causes and effects of dirt and dust.

The counter measures for the cause and effect of dirt and dust in the working environment can be identified by the operators and eliminated based on their experience. AM tags are developed and colour coded as red and white to mark any abnormality in the equipment to the maintenance personnel in the absence of the operator. These AM tags are shown on Figure 3 that can be used between operators of different shifts or with the maintenance personnel. The key part in this step is not to clean for the sake of cleaning, but to clean for inspection with high standards. As the team begins to clean they will identify defects. It can be wear and tear in equipment, loose or lost nuts and bolts due to vibrations, lubricant leakages or dirt and dust on machine parts which hide the parts to be inspected.

The causes of such defects or problems should be found and countermeasures should be applied. The defects can be divided into two different categories, the first kind of defects are those which can be corrected by the operators themselves, while the second kind of defects are those which can only be corrected by maintenance personnel. Using tag cards can be a good idea for the second kind of defects. Operators are instructed to tag the location of each abnormality as it is spotted, using a card that shows when it was found, the operator who found it and nature of the problem. This enables everyone to see what the machine status is and share and learn 
from the maintenance activities. Use white tags for problems that operators can handle and red tags for ones that the maintenance department will handle. Tagging takes problems out of both individual operator's hands and that of maintenance personnel and introduces them to autonomous maintenance circles and involves everyone.

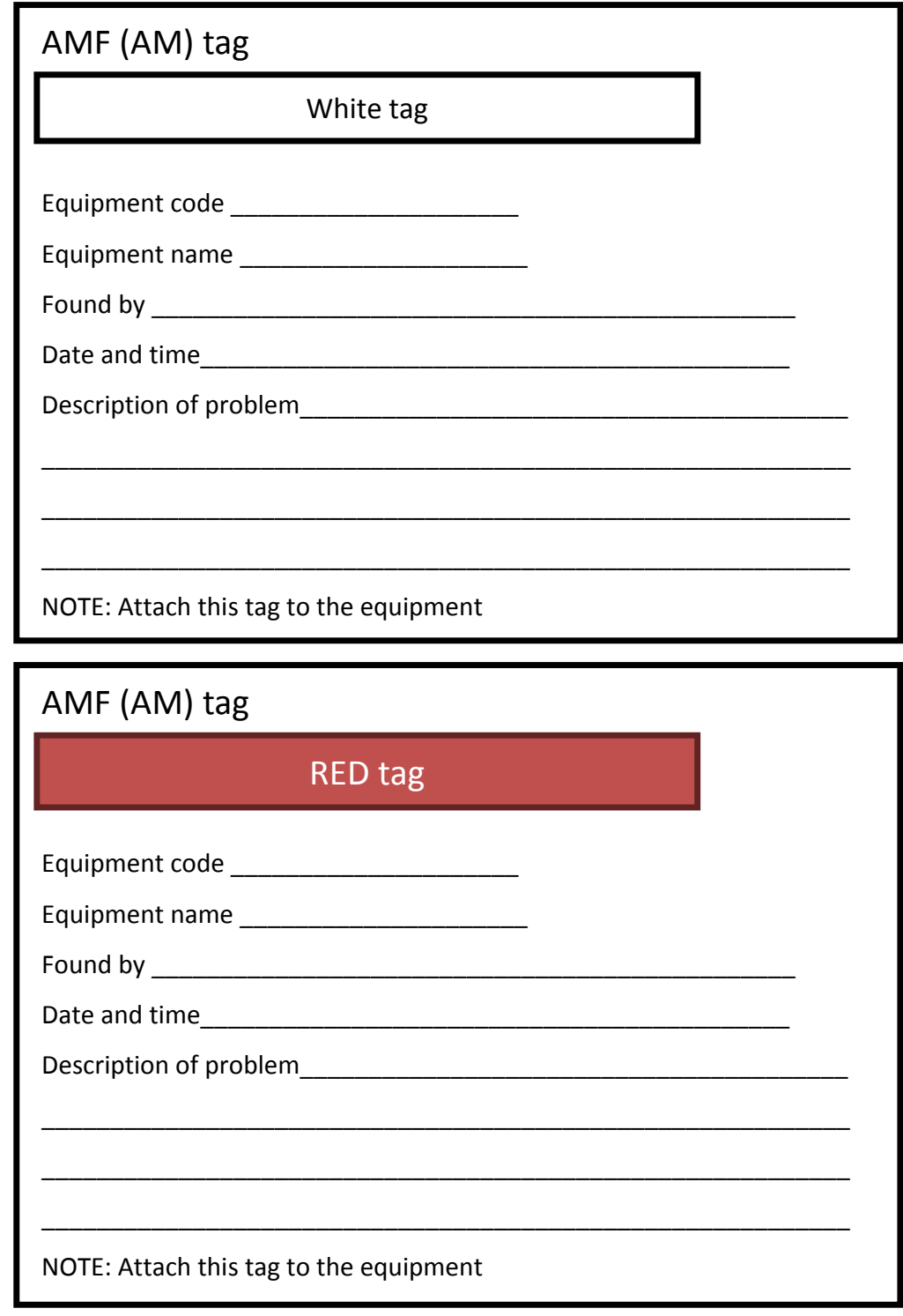

Figure 3: Red and White Tags Used for Marking the Abnormalities in Equipment

Step 3: Establishing cleaning and routine maintenance standards (checklist)

The list of cleaning and routine maintenance steps should be reviewed by the TPM team and new cleaning and maintenance standards should be set. These steps should include countermeasures for root causes of defects and cleaning routine of dusty parts. Formulate work standards that help in maintaining cleaning, lubrication and tightening levels with minimal time and effort. This gradually produces the autonomous maintenance thinking in the operator's daily routine. It also clearly demarcates the responsibilities and capabilities of operators and the maintenance personnel.

Step 4: Conducting a standards and inspection training

Top management takes the decision to implement maintenance program to reduce equipment breakdown and stoppages in the production line. If the operator is not directly involved the maintenance strategy invariably will be corrective maintenance. In fact there is three maintenance strategies such as corrective, proactive and aggressive; AM for instance is categorized under aggressive maintenance strategy. AM is focussed heavily on internal resources through total participation from all levels of employees. It ensures certain objectives and goals set by top management can be attained. However, the effort to put AM as a continuous improvement program certainly needs proper planning and execution. Therefore, training and education have become one of the important stages in autonomous maintenance. Training and promotion in AM is conducted by the introduction of the program and sustaining the maintenance with high standards. The objective of AM training and education is not only to explain AM elements and pillars but also to raise morale and soften resistance to change. A campaign to promote enthusiasm for AM implementation is organized where 
banners, signs, flags and notice boards that bear AM slogans are created in order to have a positive effect on the operator's environment. Autonomous maintenance requires teamwork from various departments such as production and maintenance to work closely to eliminate any potential breakdowns and stoppages through total commitment. The training should emphasize on standards of inspection for example the visual inspection of major parts, modification of equipment to aid inspection, finding and fixing minor defects. Inspection manuals should be developed and followed for the training.

Step 5: Carrying out an autonomous equipment inspection

Cleaning, lubrication and inspection standards should be practiced to maintain optimal equipment conditions. A review of equipment and human factor should be carried out to fix problems.

Step 6: Organization and standardization of the workplace

Improve work effectiveness, product quality and safety through work place organization and housekeeping. Set and practice control standards for raw material, work in progress, tools and spare parts.

Step 7: Continuous improvement of policies, standards and equipment

Pinpoint the weaknesses in equipment and give suggestions in meetings to improve them to simplify the operations and increase reliability.

\section{ASSELA MALT FACTORY}

The history of preparing malt in Ethiopia was started in 1974 at St. George Brewery; AMF was established in 1984 with the aim of supplying malt to local breweries. AMF is located in south-eastern part of the Ethiopia $162 \mathrm{~km}$ from the capital city Addis Ababa and $7 \mathrm{~km}$ from Assela town. The production of malt over the years has increased by $22 \%$. In total it has 223 employees (184 male and 39 female) from which 104 workers (103 male and 1 female) are working in production department and 119 workers (81 male, 38 female) are supportive staff.
AMF can be broadly divided into main section and general utilities section. These two divisions together have seven plants as listed below:

- Machine tower and silo (main plant)

- Steeping plant (main plant)

- Germination plant (main plant)

- Kiln plant (main plant)

- Cooling plant (General utilities)

- Water treatment plant (General utilities)

- Boiler Plant (General utilities)

\section{Boiler Plant}

AMF boiler is a horizontal, multi tubular and two pass packaged type boiler that uses furnace oil as fuel. There are 147 tubes in first pass and 143 tubes in second pass. Combustion of fuel takes place in furnace, hot gases flows through boiler tube and water is contained in shell. Heat transfer takes place from hot gases to water/steam. Evaporative capacity of boiler is $10,000 \mathrm{~kg} / \mathrm{hr}$. The water from the supply is found to have temporary hardness that can be softened by addition of certain chemicals. The feed water to the boiler is first softened by the water softener equipment.

There are two steam generating boiler plants in the factory, each works in shifts as per the requirements of batch processing of malt in the kiln plant. The steam production of each boiler (nominal) 6 to 7 tons per hour, design pressure 10 bar, feed water temperature (maximum) $180 \mathrm{C}$, combustion efficiency $80 \%$. Boiler plant is typically operational for 17 hours for one kiln box, and average amount of malt product $70,000 \mathrm{~kg}$. Kiln temperature level requirements vary with time. The initial 9 hours need low temperature, following 4 hours the kiln plant is at medium temperature, and final 3 hours kiln is maintained at high temperature. The furnace of the boiler can be categorized into three main components namely, control and safety mechanism, rotary cup atomizer and ignition of furnace.

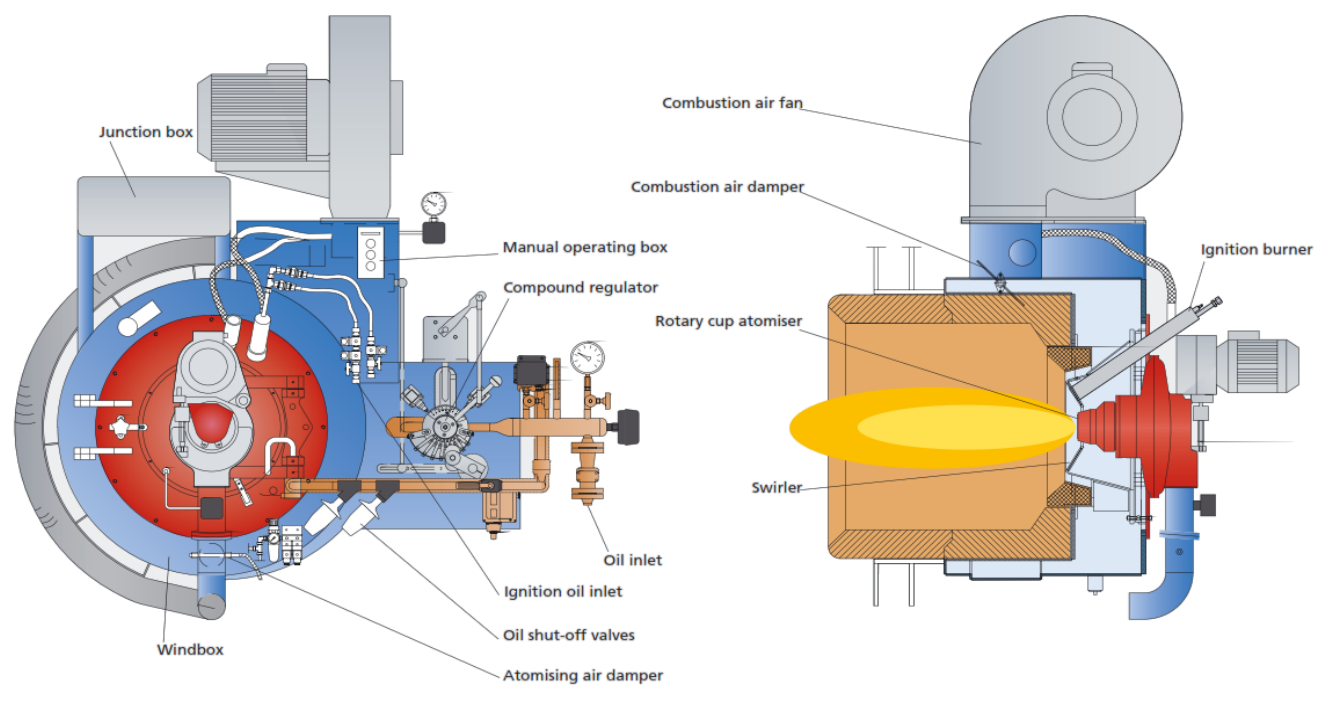

Figure 4: Schematic of Rotary Cup Atomizer and the Steam Generator Body (picture credit: AALBORG industries) 


\section{The Choice of Boiler Plant}

Boiler plant was selected for the autonomous maintenance study for these reasons.

1. The boiler plant is a general utility and downtime of this plant directly affects the malt production

2. Constant maintenance is necessary for the continuous operation of the plant.

3. The boiler plant is one of the main contributors for product quality and customer satisfaction.

Some of the main problems associated with the boiler plant are listed below:

1. Negligence of continuous follow-up and care causes consumption of additional fuel.

2. Boiler malfunction reduces the quality of product and can reduce customer satisfaction.

3. Leakage of furnace oil from intake causes water pollution in the plant vicinity. Environmental studies in literature indicate that one liter of furnace oil pollutes one million liters of water. [13]

4. Inadequate handling and operation of water softener makes the water to remain in a state of permanent hardness. These factors create accumulation of rust and dissolved oxygen that causes corrosion and reduces the life of boiler.

5. The accumulation of rust, corrosion and scale formation inside the tube can reduce normal heat transfer that increases fuel consumption adding to the cost of malt production.

6. In extreme cases rust and salt deposition can result in explosion.

7. The autonomous maintenance study also focused on the furnace rotary cup atomizer due to its high down time. A schematic of the furnace atomizer is shown in figure 4 .

\section{AutONOMOUS MAINTENANCE APPROACH}

At AMF, autonomous maintenance was implemented by working on the Focused improvement pillar of the TPM procedure.

\section{Focused Improvement Pillar (Kobetsu Kaizen)}

Focused improvement includes all activities that maximize the overall equipment effectiveness and processes. It achieves these by thorough elimination of losses and improvement of performance. The objective of focused improvement is to make sure the equipment's daily performance is the same as the performance on its best day. [3] The fact is machines do virtually 100 percent of the product manufacturing work. The only thing we people do, whether we're operators, technicians, engineers, or managers, is to tend to the needs of the machines in one way or another. The better our machines run, more is the productivity of our shop floor and more will be the success our business. [14] The driving concept behind losses may be either a functional loss (inability of equipment to execute a required function) or a function reduction (reduced capability without complete loss of a required function).
Focused improvement is aimed at zero losses, both functional and function reduction. Maximizing equipment effectiveness requires the complete elimination of failures, defects, and factors causing failures; in other words, the wastes and losses incurred in equipment operation. [2]A critical TPM paradigm shift is the core belief of focused improvement. [14] This can be summarized as follows:

- Old paradigm new equipment is the best it will ever be.

- New paradigm new equipment is the worst it will ever be.

The more we operate and maintain a piece of equipment, the more we learn about it. We use this knowledge to continuously improve our maintenance plan and the productivity of the machine. We would only choose to replace a machine should its technology become obsolete, not because it has deteriorated into a poorly performing machine. The proper implementation of focused improvement methodologies yield short term and long term improvements in equipment capacity, equipment availability, and production cycle time. [15] Focused improvement has been, and still is the primary methodology for productivity improvement in the manufacture of microchip devices. Overall Equipment Effectiveness (OEE) is the key metric of focused improvement.

\section{Specific Steps taken for Improvement at AMF}

Four levels of planning and implementation were aimed at $\mathrm{AMF}$, these are listed below:

Level 1

Create awareness; Recognize deterioration and improve equipment to prevent it:

- $\mathrm{AM}$ awareness was created through banners, posters, streamers and flyers throughout the plant especially in the production lines.

- Watch for and discover abnormalities in equipment operation and components.

- Understand the importance of proper lubrication and lubrication methods.

- Understand the importance of cleaning, inspection and proper cleaning methods.

- Understand the problem of contamination and the ability to make localized improvements.

Level 2

Understand equipment structure and functions:

- Understand what to look for when checking mechanisms for normal operations.

- Clean and inspect to maintain equipment performance.

- Understand criteria for judging abnormalities.

- Confidently judge when equipment needs to be shut off.

- $\quad$ Some ability to perform breakdown diagnosis. 
Level 3

Understand causes of equipment induced- quality defects:

- Physically analyze problem related- phenomena.

- Understand the relationship between characteristics of quality and the equipment.

- Understand tolerance ranges for static and dynamic precision and how to measure such precision.

- Understand causal factors behind defects.

Level 4

Perform routine repair on equipment:

- Be able to replace parts.

- Understand life expectancy of parts.

- Be able to deduce causes of breakdown.

Daily checklist for boiler equipment was made for employees working with the boiler plant. Along with the daily check list weekly checklist and emergency checklist were prepared. These are shown here for completeness.

- Observe/check the switching points of the water level regulator

- Observe the switching points of the temperature or pressure regulator respectively.

- Check easy movement of the burner control (control elements for air and fuel).

- Check combustion air fan, ignition and/or ventilation fan for easy turning and power transmission (V-belt).

- Check tightness of control device and/or intermediate venting.

- Check ignition device.

- Check pre- pump ventilation.

- Check flame detection unit.

- Examine combustion quality.

- Purge water level gauge.

- Check temperature or pressure limiter for changes of the set values (test keys).

- Operate draining and desalting device.

- Examine feed water and boiler water by means of chemical analysis.

- Check boiler water monitoring devices for infiltration of foreign substances by means of the test key.

- Other tests and maintenance to be performed at regular intervals:

- Check boiler valves for tightness.

- Check feeding and recirculation device by alternate operation.

- Check tightness and easy movements of fuel tank, fuel lines as well as mountings.

- Check fuel pressure indicator.

- Examine combustion chamber and flue gas passes.

- Check vent safety valves.

- Check water level limiter by lowering the water level (LWL).

- Control of the temperature and pressure indicators via, precision thermometer respectively manometer.

- Close and open the flue gas tap in order to check the limit switch.
- Interrupt the impulse line of the air pressure flow indicator and the air pressure control device at the burner.

- Check fuel shut-off device.

- Check easy movement and tightness of the safety shut-off device upstream of the burner.

- Check gas ignitions control device and intermediate venting respectively.

- Operate main cut-out.

- Check ignition device.

- Check pre- purge ventilation.

- Check flame detector by blacking out the flame sensor.

- Examine combustion quality.

\section{Weekly Check List for Work Stations}

- $\quad$ Check the joint of the pipe lines, if it has any defects or not?

- Clean the around of the pipe lines, ensure that there are no leakages on the floor.

- Take the filters out and clean it.

- Clean the track of the furnace fuel lines and burner surroundings.

- Check the steam pipe, ensure that is not defected.

\section{Weekly Checklist for Boiler Equipment}

- In case of steam boiler which can be switched from high to low pressure, the limiters must be checked at least during each operating period, however at least weekly in case of low pressure operation.

In Case of Emergency

- Switch off main cut-out.

- Cut off fuel supply.

- In case of water shortage water shortage and damage to the boiler do not refill boiler.

- Release boiler pressure and report to the supervisor respectively to the local boiler authority.

\section{AutONOMOUS MAINTENANCE RESUlTS}

Calculations on OEE of the boiler plant for January, 2011:
Mechanical breakdown
$=44 \mathrm{hrs}$. and $40 \mathrm{~min}$
Electrical breakdown
$=22 \mathrm{hrs}$. and $30 \mathrm{~min}$
Electronics breakdown
$=7 \mathrm{hrs}$.
Total breakdown
$=74 \mathrm{hrs}$. and $10 \mathrm{~min}$
Setup and other conditions
$=7 \mathrm{hrs}$. and $30 \mathrm{~min}$
Total loss
$=81 \mathrm{hrs}$. and $40 \mathrm{~min}$
Total good hours
$=720 \mathrm{hrs}$.

Net loss $($ Total good hours - Total loss $)=720$ hrs. -81 hrs. and $40 \mathrm{~min}=638 \mathrm{hrs}$. and $20 \mathrm{~min}$.

Availability

$$
\left(\frac{\text { Net Loss }}{\text { Total good hours }}\right) \times 100=\frac{638.2}{720} \times 100=88.64 \%
$$

Defected steam $=$ total breakdown $\mathrm{X}$ steam produced per hour 
Percentage of quality steam produced

$\frac{\text { Total steam produced }- \text { defected steam }}{\text { Total steam produced }}=\frac{7200-741}{7200}$ $=89.71 \%$

Performance rate: Management loss $=90$ hours

Startup loss $=15$ hours.

Performance rate: $\frac{\text { Net loss }- \text { (management loss +startup loss ) }}{\text { Net loss }}$

$$
\frac{638.20-(90+15)}{638.20}=83.55 \%
$$

Table 1: OEE Calculations for the Select Months during the Project

\begin{tabular}{|c|c|c|c|c|}
\hline Month & Total loss (hrs:mins) & Availability (\%) & Performance rate (\%) & OEE (\%) \\
\hline January 2011 & $81: 40$ & 88.64 & 83.55 & 66.44 \\
\hline February 2011 & $64: 41$ & 90.99 & 83.97 & 70.35 \\
\hline March 2011 & $62: 48$ & 92 & 84.02 & 70.80 \\
\hline April 2012 & $56: 29$ & 92.13 & 84.17 & 72.31 \\
\hline May 2012 & $42: 40$ & 94.06 & 84.49 & 75.60 \\
\hline June 2012 & $23: 55$ & 97.74 & 84.91 & 80.23 \\
\hline
\end{tabular}

Table 2: This Table is in not Compatible for Double Column Format

\begin{tabular}{|c|c|c|c|c|c|}
\hline Description & Units & Before AM application & After AM application & Change (\%) & Remarks \\
\hline Breakdown & Hours / month & 186.39 & 99.94 & 46.38 & Decrease \\
\hline Average capacity & Tons / month & 2185.12 & 2394.57 & 8.75 & Increase \\
\hline Prod. capability & Tons /month & 2100.10 & 2207.05 & 4.85 & Increase \\
\hline Machine idle & Hours/month & 54.00 & 58.70 & 8.01 & Increase \\
\hline Maintenance cost & USD / month & 520 & 185 & 64.42 & Decrease \\
\hline
\end{tabular}

[3] Suzuki, T. Ed. "TPM in process industries. Portland, Productivity Press, TPM implementation. A Japanese approach" New York, McGraw-Hill, 1994.

\section{CONCLUSION AND FUTURE ENHANCEMENT}

Asella malt factory has implemented the autonomous maintenance principles in their boiler plant. Marked improvements in average capacity, production capacity and decrease in breakdowns and maintenance costs can be observed in the table 2. A successful implementation of autonomous maintenance paves way for further implementation of TPM principles and this will further improve the employee's morale and helps in quickly achieving the set goals.

\section{ABBREVIATION}

TPM

$\mathrm{AM}$

AMF

OEE

APC

SPC

IPC
Total production maintenance

Autonomous maintenance

Asella malt factory

Overall equipment effectiveness

Automated process control

Statistical process control

Integrated process control

\section{ACKNOWLEDGMENT}

The authors like to thank the Assela malt factory for allowing the research to be conducted.

\section{REFERENCES}

[1] Ahuja, I. P. S., andKhamba, J. S.“Total productive maintenance: literature review and directions", International Journal of Quality \& Reliability Management, Volume 25, Issue 7, Pp709-756, 2008

[2] Nakajima, S "Introduction to total productive maintenance" Cambridge, MA, Productivity Press, 1988.
Consumption of furnace oil, per batch $=5550$ Liters

Consumption of furnace oil, per month $=210316$ Liters

Availability $\times$ performance rate $\times$ Quality rate $\times 100$

$$
0.8864 \times 0.8355 \times 0.8971 \times 100=66.44 \%
$$

OEE less than $85 \%$ indicates improvements are required urgently. [10]
Overall Equipment Effectiveness:

[4] Shirose, K. "TPM new implementation program in fabrication and assembly industries" Japan Institute of Plant Maintenance, Tokyo, Japan, 1996.

[5] Rose, E., Odom, R., Dunbar, R., andHinchman, J. "How TOC \& TPM work together to build the quality toolbox of SDWTs", In Electronics Manufacturing Technology Symposium, 'Manufacturing TechnologiesPresent and Future', Seventeenth IEEE/CPMT International Pp. 56-59, 1995

[6] Schippers, W. A. "An integrated approach to process control. International Journal of Production Economics", Volume 69, Issue 1, Pp93-105, 2001

[7] Pomorski, T. "Change management for organizational continuous improvement: literature review", Cincinnati, OH. The Union Institute and University, 2002.

[8] Kutucuoglu, K.Y., Hamali, J., Irani, Z. and Sharp, J.M. "A frame work for managing maintenance using performance measurement system", International Journal of Operations and Production Management, Volume 21, Number.1, Pp. 173-194, 2001.

[9] Riis, J. O., Luxhøj, J. T., andThorsteinsson, U. “A situational maintenance model", International Journal of Quality \& Reliability Management, Volume 14, Issue 4, Pp 349-366, 1997

[10] Laughlin S. "A holistic approach to overall equipment effectiveness" Computing and Control Engineering Journal, Volume 14, Number. 6, Pp. 37-42, 2004

[11] Japan Institute of Plant Maintenance (JIPM), Edition. "Autonomous maintenance for operators", Portland, Productivity Press, 1997.

[12] Ireland. F., Dale. B.G., "A study of total productive maintenance implementation", Journal of Quality in Maintenance Engineering, Volume 7, Issue: 3, Pp.183 - 192, 2001

[13] Zhenhua L. "Augmentation of laminar forced convective heat transfer of an oil flow in an enhanced tube by EHD effect",Journal of Heat Transfer, Volume. 126/131, Pp. 4, 2004.

[14] Thomas, P. "TPM/productivity improvement at advanced micro devices fab" Volume 25. Austin, TX, Advanced Micro Devices, 2003.

[15] Leflar. J. A., "Practical TPM: the method for success at Agilent Technology," ISBN: 0-56327-242-3 
Melesse Workneh Wakjira was born in July 1975, at NegelleBorena, Ethiopia. He received his Bachelors in Manufacturing Technology from Bahirdar University, Engineering Faculty, Ethiopia. He has received Masters of Science from Adama Science and Technology, Ethiopia. He has worked in Assela TVET College, AthletKenenisa Polytechnic College, and Adama Science and Technology University. He has published his research in Global Journal of Researches in Engineering.

Dr. Ananth Shalvapulle. Iyengar was born in November, 1979 at Bangalore, India. He received his Bachelors of Engineering from Bangalore University, Masters of Science from The University of Texas at El Paso, and Doctorate in Mechanical Engineering from Case Western Reserve University (CWRU). He has worked as Research Associate at CWRU, Associate Professor at Mangalore Institute of Technology and Engineering, and Team Lead (predictive engineering) at Axiom Consulting, Bangalore. He is presently working as Assistant Professor at Adama Science and Technology University. He has 3 journal publications and 6 conference publications. 